\title{
Clinical Properties and Efficacy of MTA VS Biodentine VS GIC in Repairing Root Perforations
}

\author{
Hatem Mansoor Abualhasan', Badr Soliman Alhussain²* \\ ${ }^{1}$ Dentistry Specialist Center, Tabuk, Saudi Arabia. ${ }^{2}$ Consultant Restorative Department, PSMMC, Riyadh, Saudi Arabia.
}

\section{Abstract}

Root perforation is any condition be it pathologic or accidental exposure that leads to direct communication between pulp and periodontal as a result of reabsorption, iatrogenic, or dental caries. The study aims to establish the efficacy and clinal properties of MTA, Biodentine, and GIC in repairing root perforations. The systematic review was the method that was used and articles were selected from previous kinds of literature abiding by the inclusion and exclusion criteria to ensure that only articles with relevant information are considered for review. This systematic review utilized the Reporting Items for Systematic Reviews and Meta-Analyses (PRISMA) guidelines. The focused question is: which material is the most effective in repairing root perforations between MTA, Biodentine, and GIC. The findings show that biodentine was preferred more $t$ than MTA and GIC since most of the studies roots for biodentine. Biodentine reports better clinical outcomes compared to GIC and MTA in repairing root perforations. The systematic review uncovered that most of the previous researches found biodentine to exhibit better clinical outcomes. Therefore, clinical practices can leverage this study to guarantee better clinical outcomes when dealing with root perforation repair.

Keywords: MTA, Biodentine, GIC, Root perforatioftgns

\section{INTRODUCTION}

Root perforation is any condition be it pathologic or accidental exposure that leads to direct communication between pulp cavity and periodontal tissues as a result of reabsorption, iatrogenic, or dental caries [1, 2]. Root perforation is believed to be one of the most unprecedented accidents that happen during endocrine treatment subsequently several prominent clinicians and endodontic subspecialties see this condition as challenging. Mangala and Pawar (2020, P.658) note that having a very pleasing and tasteful condition requires one to maintain functional and characteristic Dentition [3]. However, on the course of endodontic treatment, many unprecedented situations can happen such as punching of the root water divider. Wavdhane et al. (2020, P.4) acknowledge how difficult is the repair of perforation by a dentist [4].

As Mangala and Pawar (2020, P.658) highlight, endodontic treatment's main objective is to make sure that all microorganisms present within the root cavity/canal are cleaned and also the root trench framework is sealed viably [3]. However, endodontic punctures cause the epithelium to be multiplied, damage the periodontal accessibility, bone problems, and bacterial invasion, which can subsequently lead to an inevitable loss of teeth. Furcation punctures are believed to be the major iatrogenic challenges capable of triggering endodontic diseases [3]. Root canal treatment (RCT) is a procedure that encompasses many steps even more dependable and yet one of the most problematic procedures. It is imperative to assess root canal systems and also the presence of confluence apices, estimate distance towards root end, and check for symmetry between bilateral teeth. Therefore, it is important to fix these punctures with the most appropriate materials to achieve successful treatment.

Several materials have been introduced to treat problems related to the root aperture but despite the effort, none of the materials was shown to restore punctured furcations appropriately. The materials were namely; Glass Ionomer concrete, Zinc Phosphate concrete, Light Cure Glass Ionomer, Amalgam, Indium Foil, Cavit, and Calcium hydroxide, among others [3]. The challenges faced by these materials are they do not seal the correspondence hidden tissues and the root hole. Therefore, advanced materials were

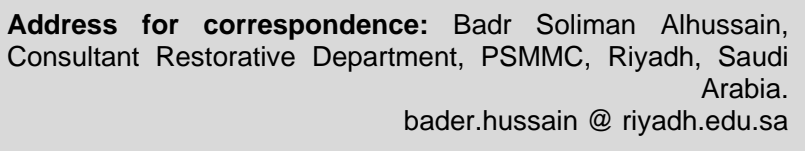

This is an open-access article distributed under the terms of the Creative Commons Attribution-Non Commercial-Share Alike 3.0 License, which allows others to remix, tweak, and build upon the work non commercially, as long as the author is credited and the new creations are licensed under the identical terms.

How to cite this article: Abualhasan $\mathrm{H} \mathrm{M}$, Alhussain B S. Clinical Properties and Efficacy of MTA VS Biodentine VS GIC in Repairing Root Perforations. Arch. Pharm. Pract. 2022;13(1):537. https://doi.org/10.51847/46MIz4Calq 
needed to break the current gap that exists when it comes to puncturing, including Mineral Trioxide Aggregate (MTA), Glass Ionomer Cement (GIC), and Biodentine. Alghamdi and Aljahdali (2019, P.471) and Alazrag et al. (2020) emphasize that the ideal perforation repair material should be characterized by biocompatibility, radiopaque, proper sealing, not absorbable, and allow for easy manipulation [1, 5]. The purpose of this systematic review is to establish the efficacy and clinal properties of MTA, Biodentine, and GIC in repairing root perforations.

\section{Materials and Methods}

This systematic review utilized the Reporting Items for Systematic Reviews and Meta-Analyses (PRISMA) guidelines. The focused question is: which material is the most effective in repairing root perforations between MTA, Biodentine, and GIC?

\section{Search Strategy}

The search was performed to find quality articles that can be used to provide quality information about the repairing of root perforations. The information was searched in different databases such as Google Scholar, ProQuest, and PubMed. Various keywords were used during the search. They include "root perforation," "biodentine," repair material," "Glass Ionomer Cement," and "Mineral Trioxide Aggregate."

\section{Inclusion Criteria}

The inclusion criteria entailed various conditions that the selected articles were supposed to meet. First, all studies included were in the English language, with a timeframe of between 2019 and 2021. Second, studies that were carried out on animals and human beings were considered for review. Third, before any article could be selected, it must address either biodentine, Glass Ionomer Cement, or Mineral Trioxide Aggregate, or all of them. Finally, only full-text articles were eligible to be considered for review.

\section{Exclusion Criteria}

The first exclusion criteria entailed articles that focused on other repair materials without mentioning biodentine, Glass Ionomer Cement, or Mineral Trioxide Aggregate. The second element of exclusion is studies that concentrated on the different clinical applications of repair materials without a clear focus on root perforation. The strategy was to ensure that the selected articles are relevant and provide the needed information to establish facts related to MTA, GIC, and biodentine. Finally, other articles that were not considered include commentary articles, surveillance reports, and perspectives.
All studies selected were evaluated to determine whether they meet the inclusion criteria. Some articles were assessed by reading the abstract and establishing where the summary provided captures the keywords of the topic. Other articles were investigated in-depth since their topics were not descriptive enough to reveal all the details discussed in those materials. Furthermore, the references used in the studies were examined to establish whether they are from reputable databases and written by acknowledged professionals. Most importantly, all articles selected for review were peerreviewed. This move was meant to guarantee that only reputable and reliable data can be used to accomplish the objectives of this systematic review. The relevance of each article was examined and studies that satisfied the set criteria for inclusion were scheduled for review. After screening, a total of 20 articles were picked from a pool of 150 studies. The PRISMA flowchart in Figure 1 below displays the eligibility criteria for the exclusion and inclusion of articles based on relevance.

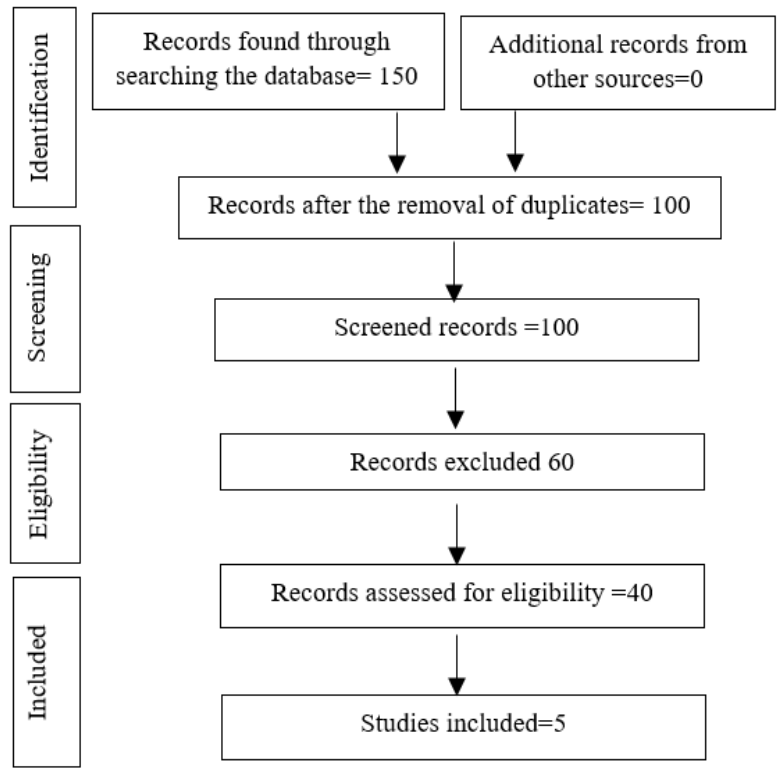

Figure 1. Eligibility criteria for inclusion and exclusion based on PRISMA guidelines

\section{Bias Risk Assessment}

A bias risk assessment was conducted on all the selected articles utilizing the Cochrane risk of a bias assessment tool. This form of bias assessment is based on five domains that include reporting, attrition, performance, selection, and other bias. Therefore, the assessment of bias is done as a verdict of high, low, or unclear. Table 1 below shows the Cochrane risk of bias assessment. Table 2 shows the overall risk of bias judgment.

Table 1. Cochrane Risk of bias assessment

Domain

Description

High risk of bias

Low risk of bias

Unclear risk of bias

Reviewer assessment 


\begin{tabular}{|c|c|c|c|c|c|}
\hline $\begin{array}{l}\text { Selection bias } \\
\text { Random sequence } \\
\text { generation }\end{array}$ & $\begin{array}{l}\text { Describes the methods utilized to } \\
\text { create an allocation sequence to } \\
\text { establish whether comparable } \\
\text { groups should be produced. }\end{array}$ & $\begin{array}{l}\text { Insufficient creation of } \\
\text { random sequence } \\
\text { implies selection bias }\end{array}$ & $\begin{array}{l}\text { Comparable groups } \\
\text { should be produced for } \\
\text { random sequence } \\
\text { generation. }\end{array}$ & $\begin{array}{l}\text { Not described in } \\
\text { enough details }\end{array}$ & Judgment \\
\hline $\begin{array}{l}\text { Selection bias } \\
\text { Allocation } \\
\text { concealment }\end{array}$ & $\begin{array}{l}\text { Methods used to conceal } \\
\text { allocation described }\end{array}$ & $\begin{array}{c}\text { Inadequate } \\
\text { concealment implies } \\
\text { selection bias }\end{array}$ & $\begin{array}{l}\text { A possibility of failing } \\
\text { to foresee intervention } \\
\text { allocations }\end{array}$ & $\begin{array}{l}\text { Not enough } \\
\text { details }\end{array}$ & Judgment \\
\hline $\begin{array}{l}\text { Reporting bias } \\
\text { Selective } \\
\text { reporting }\end{array}$ & $\begin{array}{l}\text { Should state the examination of } \\
\text { selective outcome reporting }\end{array}$ & $\begin{array}{l}\text { Selective outcome } \\
\text { reporting leads to } \\
\text { reporting bias }\end{array}$ & $\begin{array}{l}\text { No detection of } \\
\text { reporting bias linked to } \\
\text { selective outcomes }\end{array}$ & $\begin{array}{l}\text { Not enough } \\
\text { details }\end{array}$ & Judgment \\
\hline Other bias & $\begin{array}{l}\text { Any other issues related to bias } \\
\text { not covered }\end{array}$ & $\begin{array}{l}\text { Bias concerns due to } \\
\text { issues not addressed in } \\
\text { other places }\end{array}$ & $\begin{array}{l}\text { No detection of other } \\
\text { bias }\end{array}$ & $\begin{array}{l}\text { Insufficient } \\
\text { information to } \\
\text { reveal other bias }\end{array}$ & Judgment \\
\hline
\end{tabular}

Table 2. The overall risk of bias judgment

\begin{tabular}{ccc} 
Study & Risk of bias judgment & Justification \\
\hline$[1]$ & Low risk of bias & No detection of any form of bias for the study. \\
{$[3]$} & Low risk of bias & No form of bias can be detected in the article. \\
{$[6]$} & Unclear risk of bias & Not enough details to reveal selection, reporting, and other biases. \\
{$[7]$} & Low risk of bias & Selection and reporting bias was not spotted in the study. \\
{$[8]$} & Unclear risk of bias & The study does not describe how the different forms of bias have been addressed. \\
\hline
\end{tabular}

\section{Results And Discussion}

The exploration conducted resulted in twenty studies that met the inclusion and exclusion criteria. In total, 150 articles matched the search approach based on the picked keywords. However, after the removal of duplicate records 100 articles were selected for screening, out of which 60 studies were excluded. At this point, 40 articles were eligible for assessment since they were full articles. Out of the 40 studies, 5 qualified to be included in the qualitative synthesis. Specifically, these studies focused on MTA, GIC, and biodentine, and how they are used in root perforation. The studies collected articles include In-vivo studies, In-vitro studies, retrospective clinical studies, and randomized controlled trials (RTC). The majority of the articles addressed more than one element of interest. For instance, some articles compare biodentine and GIC, others compared MTA and GIC, while others compared biodentine and MTA. Other studies addressed either MTA, GIC, or biodentine, while other articles compared either GIC, MTA, or biodentine with other materials used for root perforation. Table 4 below shows a summary of the studies (Table 3).

\begin{tabular}{|c|c|c|}
\hline Author and year & Inclusion criteria & Findings \\
\hline [1] & Addressed MTA and Biodentine & $\begin{array}{l}\text { There is no unanimity in regards to the most suitable repair } \\
\text { material for root perforation. }\end{array}$ \\
\hline [3] & Addressed Biodentine, MTA, and GIC & $\begin{array}{l}\text { Biodentine is superior to MTA in perforation sealing even } \\
\text { though the difference is insignificant statistically. }\end{array}$ \\
\hline$[6]$ & Addressed Biodentine and MTA. & $\begin{array}{l}\text { Biodentine is better than MTA for root-end filling due to the } \\
\text { least margin gap at the edge. }\end{array}$ \\
\hline [7] & $\begin{array}{l}\text { Focused on MTA and Biodentine, among other } \\
\text { root perforation filling materials }\end{array}$ & $\begin{array}{l}\text { Based on the leakage mean, MTA samples showed better } \\
\text { results with a reduction in the value of leakage mean after a } \\
\text { month compared to Biodentine. }\end{array}$ \\
\hline$[8]$ & Addressed Biodentine, GIC, and Pro-Root MTA & $\begin{array}{l}\text { Biodentine showed better results compared to Pro-Root MTA } \\
\text { and resin-modified GIC concerning sealing ability. }\end{array}$ \\
\hline
\end{tabular}

Based on the synthesized studies, various facts emerged with the bottom line being that the physical and chemical properties of the materials used affect the root perforation prognosis. The purpose of this systematic review was to gather data about the different materials leveraged for root perforation repair. The systematic review summarized, appraised, and synthesized high-quality research evidence from 20 articles to establish the most appropriate material that can be used for root perforation therapy. The general 
outcomes show that the reviewed studies confirmed diverse repair materials utilized for root perforation.

A study by Alghamdi and Aljahdali (2019, P.474) established that there is no unanimity in regards to the most suitable material that can be utilized for the treatment of root perforation [1]. Alghamdi and Aljahdali (2019, P.474) claim that some of the studies reviewed in their research revealed that the assessment of the sealing capacity of biodentine and MTA led to the declaration that no considerable differences were noticed between the two materials, with biodentine being preferred as an alternative to MTA [1]. Mangala and Pawar (2020, P.660) concluded that light-cured GIC allows more amount of dye leakage as opposed to biodentine and MTA [3]. Bansal et al. (2019, P.10) found out that biodentine was superior to MTA Plus and ProRoot MTA after it exhibited a reduced hole at the edge of the root-end and dentin filling materials [6]. Also, Nabeel et al. (2019, P.20) rooted for biodentine in peri-radicular surgeries instead of ProRoot MTA despite the latter exhibiting greater sealing ability [7].

On the other hand, Mohan et al. (2021, P.82) assert that MTA provides a more efficient root perforation restoration compared to other perforation repair materials [8]. Grover et al. (2020), Kakani et al. (2020), Tang et al. (2019) hold that biodentine has a better sealing ability compared to MTA [911]. Francis et al. (2019, P.34) claim that for large furcal perforations, the sealing ability of biodentine and MTAAngelus shows no significant difference [12]. However, in support of MTA, Jian et al. (2019) affirm that the repair efficiency of MTA has a positive correlation with perforation diameters, repair materials, and ages of patients [13]. Bossù et al. (2020) concluded that MTA is better than bioentine in the primary teeth' pulpotomy [14]. Saad (2020) note that MTA-based sealers are part of the broad category of calcium silicate-based root canal sealers [15].

On their part, Bjørndal et al. (2019) assert that biodentine can overcome some of the concerns of discoloration that characterizes MTA [16]. Arandi and Thabet (2021) support biodentine by claiming that it has a good clinical efficacy when it comes to pulp capping [17]. According to Alzahrani and Alghamdi (2021), MTA contributed to tissue healing without pain due to palpation and percussion [18]. Aldayri et al. (2019, P.10) roots for MTA in the sense that it can be utilized in "furcal perforated-pulpotomized primary molars" as a repair material [19]. Additionally, MTA can induce cementum tissue formation during its perforation repair [20].

\section{CONCLUSION}

Based on the reviewed studies, it can be depicted that biodentine is the most favored material for root perforation repair compared to MTA and GIC. The systematic review uncovered that most of the previous research found biodentine to exhibit better clinical outcomes, hence, emerging as a superior one among the three. Therefore, clinical practices can leverage this study to guarantee better clinical outcomes when dealing with root perforation repair.

ACKNOWLEDGMENTS: Authors of this study would like to acknowledge the support and cooperation of the research center of Riyadh Elm University.

CONFLICT OF INTEREST: None

FINANCIAL SUPPORT: None

ETHICS STATEMENT: None

\section{REFERENCES}

1. Alghamdi FT, Aljahdali EA. Comparison of Mineral Trioxide Uggregate, EndoSequence Root Repair Material, and Biodentine Used for Repairing Root Perforations: A Systematic Review. Cumhuriyet Dent J. 2019;22(4):469-76.

2. Jamshidy L, Amirkhani Z, Sharifi R. Effect of furcation perforation size on fracture resistance of mandibular first molar. Dent Hypotheses. 2019;10(1):9

3. Mangala TM, Pawar RR. Evaluating sealing ability of three different furcation perforation repair materials. J Crit Rev. 2020;7(7):658-1.

4. Wavdhane MB, Bansode PV, Pathak SD, Priyadarshini L. Management of Pulpal Floor Perforation Using BIODENTINE: A Clinical Report. J Med Dent Sci Res. 2021;8(2):01-5.

5. Alazrag MA, Abu-Seida AM, El-Batouty KM, El Ashry SH. Marginal adaptation, solubility and biocompatibility of TheraCal LC compared with MTA-angelus and biodentine as a furcation perforation repair material. BMC Oral Health. 2020;20(1):1-2.

6. Bansal R, Bansal M, Matta MS, Walia S, Kaur B, Sharma N. Evaluation of Marginal Adaptation of MTA, Biodentine, and MTA Plus as Root-End Filling Materials-An SEM Study. Dent J Adv Stud. 2019;7(01):006-11.

7. Nabeel M, Tawfik HM, Abu-Seida AM, Elgendy AA. Sealing ability of Biodentine versus ProRoot mineral trioxide aggregate as root-end filling materials. Saudi Dent J. 2019;31(1):16-22.

8. Mohan D, Singh AK, Kuriakose F, Malik R, Joy J, John D. Evaluation of Sealing Potential of Different Repair Materials in Furcation Perforations Using Dye Penetration: An In Vitro Study. J Contemp Dent Pract. 2021;22(1):80-3.

9. Grover R, Sadana G, Gupta S, Gupta T, Mehra M, Kaur B. Comparative evaluation of sealing ability of two different biocompatible materials in repair of furcal perforation: An In vitro study. Dent Med Res. 2020;8(2):70.

10. Kakani AK, Veeramachaneni C. Sealing ability of three different root repair materials for furcation perforation repair: An in vitro study. J Conserv Dent. 2020;23(1):62.

11. Tang JJ, Shen ZS, Qin W, Lin Z. A comparison of the sealing abilities between Biodentine and MTA as root-end filling materials and their effects on bone healing in dogs after periradicular surgery. J Appl Oral Sci. 2019;27.

12. Francis T, Joshi SB, Pai AV, Sakkir N, Thaha KA. Comparison of the sealing ability of MTA-angelus, biodentine and CEM cement in the repair of large furcal perforations-a bacterial leakage study. J Clin Diagn Res. 2019;13(1):32-5.

13. Jian SU, Yuanyuan WE, Xiaobei TI, Qinglin ME. Comparative Analysis of Clinical Effects of Mineral Trioxide Aggregate in the Treatment of Endodontic Diseases. Iran J Public Health. 2019;48(4):697.

14. Bossù M, Iaculli F, Di Giorgio G, Salucci A, Polimeni A, Di Carlo S. Different pulp dressing materials for the pulpotomy of primary teeth: a systematic review of the literature. J Clin Med. 2020;9(3):838.

15. Saad AY. Physicochemical, cytotoxicity, and biological properties of calcium silicate-based root canal sealers: A literature review. Saudi Endod J. 2020;10(3):173.

16. Bjørndal L, Simon S, Tomson PL, Duncan HF. Management of deep caries and the exposed pulp. Int Endod J. 2019;52(7):949-73.

17. Arandi NZ, Thabet M. Minimal Intervention in Dentistry: A Literature Review on Biodentine as a Bioactive Pulp Capping Material. BioMed Res Int. 2021;2021. 
18. Alzahrani O, Alghamdi F. Nonsurgical Management of Apical Root Perforation Using Mineral Trioxide Aggregate. Case Rep Dent. 2021;2021.

19. Aldayri B, Nourallah AW, Badr F. Clinical and Radiographic Evaluation of the Healing After MTA Application on Mechanical Furcal Perforations in Primary Molars-part2. Preprints. 2019;2019050322
20. Hirata-Tsuchiya S, Suzuki S, Nakamoto T, Kakimoto N, Yamada S, Shiba H. Surgical Sealing of Laterally Localized Accessory Root Canal with Resin Containing S-PRG Filler in Combination with Non-Surgical Endodontic Treatment: A Case Report. Dent J. 2020;8(4):131. 